In view of the prognostic and therapeutic implications, the possibility of a malabsorption syndrome should always be firmly excluded in patients presenting with renal tubular defects and osteomalacia before the diagnosis of an irreversible renal disorder is accepted.

A. C. MaCCuISH, M.B., M.R.C.P.ED.

J. F. MUNRO, M.B., M.R.C.P.ED.

W. L. LAMB, M.B., F.R.C.P.ED.

The Royal Infirmary, Edinburgh, EH3 9YW.

\section{Haemophilus aphrophilus Endocarditis}

British Medical fournal, 1970, 2, 344

Infective endocarditis caused by Hatmophilus aphrophilus is rare (Khairat, 1940; Toschach and Bain, 1958; Vargas et al., 1962; Keith and Lyon, 1963; Witorsch and Gorden, 1964; Dung and Lin, 1966). In only one of 1,324 cases of nonstreptococcal bacterial endocarditis reported between 1936 and 1948 was $H$. aphrophilus the causative organism (Jones, 1950).

We present a case of infective endocarditis in which $H$. aphrophilus was isolated from seven blood cultures.

\section{CASE Report}

The patient, a 57-year-old bricklayer, was admitted to the hospital because of chills, fever, "sore throat," and joint pains. Until the onset of symptoms four weeks earlier he had been fit.

On examination the only abnormal findings were a temperature of $100.6^{\circ} \mathrm{F}$. $\left(38.1^{\circ} \mathrm{C}\right.$.), hyperaemia of the pharynx, mild clubbing of the fingers, and tenderness of the left calf.

Investigations: W.B.C. $11,750 /$ cu.mm. (65\% neutrophils, 3\% bands, $26 \%$ lymphocytes, $4 \%$ monocytes, and $2 \%$ eosinophils); E.S.R. $29 \mathrm{~mm}$./hour. All other routine tests were normal.

After admission he was noted to have remittent fever with a maximum temperature of $160^{\circ} \mathrm{F}$. $\left(41 \cdot 1^{\circ} \mathrm{C}\right.$.). An unidentified Gram-negative organism was isolated from seven consecutive blood cultures. Antimicrobial therapy was then begun with a daily intravenous dose of 40 million units of aqueous penicillin and $2 \mathrm{~g}$. of chloramphenicol. Subsequently this organism was identified as $H$. aphrophilus, sensitive (in-vitro disc method*) to penicillin, tetracycline, chloramphenicol, kanamycin, nitrofurantion, colistin sulphomethate, nalidixic acid, ampicillin, and cephalothin. It was resistant to erythromycin, lincomycin, oxacillin, and sulphafurazole.

About six weeks after his admission splinter haemorrhages, retinal and conjunctival haemorrhages, and microscopic haematuria developed. An apical systolic murmur with varying intensity appeared. Haematocrit value and haemoglobin dropped to $28 \%$ and $8.8 \mathrm{~g} . / 100 \mathrm{ml}$., respectively, and blood urea nitrogen rose to $118 \mathrm{mg}$. and creatinine to $2.9 \mathrm{mg}$. $/ 100 \mathrm{ml}$. On day 42 signs of arterial occlusion involving the left lower extremity developed. Three weeks later acute congestive heart failure developed and was successfully managed with digitalis and diuretics. Ten weeks after admission, blood cultures were sterile and the patient was clinically improved. Two weeks later he was ambulatory and in apparent good clinical condition when he suddenly developed cardiac arrest. Though successfully resuscitated, he failed to regain consciousness and died 11 days later.

At necropsy the positive findings were endocarditis involving an otherwise normal mitral valve with perforation of the posterior valvular leaflet. Additional findings of interest were hypertrophy and dilatation of the heart, thrombosis of the left common iliac artery, and infarcts of the lungs and kidney. Cultures of the mitral valve were sterile.

Description of Organism.-From seven blood cultures planted

*Tube dilution method for assessing bacterial sensitivity was not available in the clinical laboratory at the time of this report.
REFERENCES

Dent, C. E. (1952). Fournal of Bone and Foint Surgery, 34B, 266.

Fanconi, G. (1936). Fahrbuch für Kinderheilkunde, 147, 299.

Muldowney, F. P., Freaney, R., and McGeeney, D. (1968). Quarterly Fournal of Medicine, 37, 517.

Wade, D. N. (1969). British fournal of Hospital Medicine, 2, 820. in thioglycolate broth $H$. aphrophilus was isolated. The organisms for the most part were coccoid with few rods and had a tendency towards granular growth along the sides of the tubes containing thioglycolate and trypticase soy broth. They were Gram-negative, non-spore forming, and non-motile. They grew out at $25^{\circ}$, $37^{\circ}$, and $42^{\circ} \mathrm{C}$. As was true of the 34 strains described by King and Tatum (1962), they did not have a growth factor requirement other than carbon dioxide. They were inert in that they did not exhibit pigment and catalase formation, nor did they produce haemolysis. They did ferment lactose and dextrose with slight acid and gas formation.

\section{COMMENT}

This case is similar to the first reported case of $H$. aphrophilus endocarditis (Khairat, 1940) in that no preexisting cardiac lesion was found. In all seven cases reported subsequently pre-existing valvular defects of rheumatic origin were present. Other than acute upper respiratory disease and arthralgia a history of pre-existing disease could not be elicited. It would seem probable that the oropharyngeal route was the portal of entry of $H$. aphrophilus. A study by Page and King (1966) of 41 infections due to this organism tends to support the notion that the oropharyngeal route is the most likely portal of entry.

This is the second reported case in which $H$. aphrophilus implanted on a normal valve. It is likely that this organism does not require damaged cardiac tissue for its implantation. Clinically the course of this patient's infective endocarditis did not differ appreciably from what one might expect when a streptococcus is the causative agent. The patient responded well to therapy with penicillin and chloramphenical, sterile blood cultures being achieved after seven weeks of therapy. Though sterilization of the blood was accomplished, as often happens he succumbed to the combined effects of multiple arterial emboli and mitral valve perforation.

We are indebted to Miss Miriam Carr, chief of bacteriology section, laboratory service, New York Veterans Administration Hospital, for her assistance in isolation and identification of the organism.

Rogelio M. Pine, M.D.

HAROLD S. BALLARD, M.D., F.A.C.P. Medical Service, New York Veterans Administration Hospital, New York, New York 10010.

\section{REFERENCES}

Dung, W. M. H., and Lin, T. K. (1966). American Heart fournal, 71, 251 .

Jones, M. (1950). American Heart fournal, 40, 106.

Keith, T. A., and Lyon, S. A. (1963). American fournal of Medicine, 34,535 .

Khairat, O. (1940). Fournal of Pathology and Bacteriology, 50, 497.

King, E. O., and Tatum, H. W. (1962). Fournal of Infectious Diseases, 111, 85.

Page, M. I., and King, E. O. (1966). New England fournal of Medicine, 275,181 .

Toschach, S., and Bain, G. O. (1958). American fournal of Clinical Pathology, 30, 328.

Vargas, L., Gilabert, B., and Kohan, R. (1962). Revista Chilena de Pediatria, 33, 183.

Witorsch, P., and Gorden, P. (1964). Annals of Internal Medicine, 60, 957. 